\title{
Accumulation of americium 243 in selected brackish and marine invertebrates
}

\author{
C. N. Murray ${ }^{1}$, M. Hoppenheit ${ }^{2} \&$ H. Rade ${ }^{2}$ \\ ${ }^{1}$ Commission of the European Communities, Joint Research Centre, \\ Ispra Establisbment, Division of Chemistry; I-21020 Ispra(Varese), Italy, \\ and \\ ${ }^{2}$ Biologische Anstalt Helgoland (Laboratorium Sülldorf); \\ Wüstland 2, D-2000 Hamburg 55, Federal Republic of Germany
}

\begin{abstract}
As an initial step in a programme designed to investigate factors which are of importance in affecting the behaviour of actinides towards certain invertebrates found in estuarine and marine environments, laboratory procedures have been developed to study the accumulation of americium in three species: the polychaete worm Nereis diversicolor, the brackish-water amphipod Gammarus duebeni and the harpacticoid copepod Tisbe holothuriae. The species chosen are considered representative of groups having wide ecological importance. It was found that large differences in concentration factors occurred for the same organisms, depending upon aging of the contaminated medium; much higher and more variable values being found when uptake was from freshly contaminated solutions than from those aged up to a week. The interaction of specimens with physico-chemical reactions of americium which appear to take place within the first few days after its introduction into water are considered to be responsible for these differences. Uptake from contaminated water that had been allowed to age in the absence of organisms appears to be unaffected by subsequent conditioning by specimens. Americium concentration factors show a strong tendency to increase with decreasing size of the species, varying from over 1000 for $T$. bolothuriae to about 3 for $N$. diversicolor. The possibility that the mechanisms regulating the uptake of actinides in different species may depend upon $\mathrm{pH}$ is briefly discussed.
\end{abstract}

\section{INTRODUCTION}

During the study of the various alternatives for the disposal of actinide containing high level wastes which will be derived from the introduction of national nuclear power programmes, it has become apparent that one option concerning the marine environment is of particular interest (Bishop, 1975; Talbert, 1976). Although our understanding of the distribution of plutonium in sea-water, sediment and marine biota is increasing and various initial studies have been undertaken on its biokinetics in a few marine organisms (Fowler et al., 1975; Ward, 1966), further information for a better understanding is required on the role that certain widely distributed aquatic species play in the cycling of plutonium and other actinides in the biosphere. This is specially needed in the case of americium and curium which are projected to make up a large 
proportion of the total alpha burden in future high level wastes (Girardi \& Bertozzi, 1974; Pigford \& Ang, 1975).

The present paper outlines the results of experimental work undertaken using americium 243. The laboratory application of this long lived isotope $\left(\mathrm{t}^{1 / 2}=7950\right.$ years, gamma emitter $75 \mathrm{keV}$ ) was made primarily to test various techniques involved with these types of studies and to identify those factors which are of importance in affecting the behaviour of actinides in aquatic ecosystems. The techniques developed will be applied in future to other gamma emitting actinide isotopes of much shorter half-lives, such as ${ }^{237} \mathrm{Pu}$ and ${ }^{242} \mathrm{Cm}$. The results presented here constitute a part of a programme on the study of biokinetics of actinide elements in estuarine and marine environments.

Three invertebrates, a polychaete worm, a brackish-water amphipod and a harpacticoid copepod, have been chosen as representative of groups of organisms of wide ecological importance. It has been shown that bottom living organisms such as polychaetes make up over $50 \%$ of the composition of macrofaunal taxa of deep-sea soft bottom communities in the Central North Pacific (Hessler, 1974). McGowen (1976) has reported that copepods are even the most numerous members of the macrozooplankton fraction of the community of the Central North Pacifik Gyre and that it is likely that they also form the largest part of the water column biomass. This area is already being studied in order to gain information that will be needed so serve as the basis for any future decision on the possible disposal of high level waste in deep ocean geological formations.

\section{MATERIALS AND METHODS}

\section{Tisbe bolotburiae}

The original material of Tisbe holothuriae Humes was supplied by Uhlig, who had initially observed this species in the open air sea-water swimming pool on the island of Helgoland (Uhlig, 1965). Previous investigations on the dynamics of exploited populations have shown that this species can easily be handled in the laboratory (Hoppenheit, 1975a, b; 1976).

In each series of experiments lasting up to ten days some 1000-1500 adult female copepods were used. They were obtained from laboratory cultures as follows: eggcarrying females were isolated before the start of the experiment, their nauplii were allowed to mature and from these populations young females were separated as required for the experiments.

In measurements on the uptake of ${ }^{243} \mathrm{Am}$ from water, the specimens were placed in $100 \mathrm{ml}$ of sea-water $(30 \%)$, which had previously been filtered through a Seitzfilter (K 5) and stored at $80^{\circ} \mathrm{C}$ for about 12 hours. The subsequent experiments were performed at room temperature (ranging from $20-25,2^{\circ} \mathrm{C}$ ) and an initial ${ }^{243} \mathrm{Am}$ ( +3 form) activity of $165-195 \mathrm{cpm} / \mathrm{ml}(90-110 \mathrm{pCi} / \mathrm{ml})$, the $\mathrm{pH}$ being carefully adjusted to 8.0 before the addition of the copepods, and a sample of water was taken immediately as control. During the first day measurements were performed at 8, 16 
and 24 hours and thereafter at approximately daily intervals. At each measurement period some 60-70 females were separated from the experimental population and were killed by washing them with $0.5 \mathrm{ml}$ alcohol. The specimens were then washed twice with $10 \mathrm{ml}$ of uncontaminated sea-water, the dead individuals being held on a $100 \mu \mathrm{m}$ mesh. A part of the second $10 \mathrm{ml}$ of water was used to wash the copepods from the mesh into a small glass beaker. From these specimens exactly 50 were placed in a counting tube using a micropipette. Each tube had been previously calibrated to hold $2 \mathrm{ml}$ liquid. The 50 copepods in $2 \mathrm{ml}$ of the second wash water were then counted for americium activity (energy ${ }^{243} \mathrm{Am}$ : $75 \mathrm{keV}$; detector efficiency $80 \%$ using a $\mathrm{NaI}$ [Tl] gamma detector); a further $2 \mathrm{ml}$ culture water which had been taken for activity measurement was returned in each case to the experimental set-up. Care was taken that evaporation did not take place from the experimental solutions by using watch glass covers. The last $2 \mathrm{ml}$ of the second $10 \mathrm{ml}$ of water used to wash the specimens were also measured in order to check that the copepods were, at this stage, uncontaminated by the culture solution; in all cases the wash water activity was indistinguishable from the background within the experimental counting error. It was thus considered that any activity measured for these specimens was due to uptake of americium from the water.

All investigations were conducted over a period of 7-10 days. As the generation time of Tisbe holothuriae is about 8 days at $22^{\circ} \mathrm{C}$ (cf. Hoppenheit, 1976), the appearance of a new generation of adults prevented the performance of studies of longer duration. At the start of the experiments the specimens were given $50 \mathrm{mg}$ dried, uncontaminated mussel (Mytilus edulis) flesh (mantle) which remained in the test solution throughout the experimental period.

In the case of uptake studies from contaminated food $50 \mathrm{mg}$ dried mussel flesh, contaminated with americium $(230 \mathrm{pCi} / \mathrm{mg}$ dry weight; wet: dry weight food ratio 5.5), was placed in $100 \mathrm{ml}$ of uncontaminated sea-water containing the specimens. The same measurements were then made daily as for the uptake studies from water. The same sampling procedure was employed, with the addition of a further filtering of the culture water through a $25 \mu \mathrm{m}$ mesh to ensure that small food particles were trapped and not counted. Tests conducted using only contaminated food and uncontaminated water showed that no food particles passed through this mesh size. Both series of uptake experiments were repeated separately three times.

Two control tests were also carried out to determine the behaviour of americium when no copepods were present. The first was designed to determine the variation of distribution of americium with time in the experimental system, in the presence of uncontaminated food and contaminated water, as percentage of activity retained on a $0.45 \mu \mathrm{m}$ filter (i.e. in solution or as colloidal material of very small size). The second control test was to measure the amount of desorption of americium from contaminated food into uncontaminated water and to determine the particle size distribution of this fraction. The results of these two control studies were used to compare the behaviour of americium in the experimental system when copepods were present. 


\section{Gammarus duebeni}

Investigations were undertaken on the uptake and loss characteristics of americium by the brackish-water amphiod Gammarus duebeni duebeni Liljeborg. Specimens used in this work were collected in the lake "Kleiner Kiel“ (connected to the Baltic Sea) in the city of Kiel. For conditions of maintaining the gammarids the reader is referred to Hoppenheit (1969).

Distinct differences in americium uptake characteristics from water have been found, depending upon whether the solution was freshly contaminated or whether it had been allowed to age for 5 or 6 days. Control experiments on the particulate formation and $\mathrm{pH}$ variation of contaminated brackish-water solutions without the presence of specimens were carried out for comparison with uptake data.

For uptake from freshly prepared water, male Gammarus duebeni at various stages of their moulting cycles and all about the same size were introduced into small perforated plastic tubes (diameter $3 \mathrm{~cm}$, height $3 \mathrm{~cm}$ ) which had been earlier placed in a plastic basin containing $200 \mathrm{ml}$ filtered (Seitz-filter K 5) brackish water of $10 \%$ contaminated a few minutes previously with americium, the solution being adjusted after addition of activity to $\mathrm{pH}$ 8.0. Immediately after the adjustment of the $\mathrm{pH}$ and before the addition of the specimens $1 \mathrm{ml}$ of the freshly contaminated water was taken as zero-day standard (approximately $1300 \mathrm{cpm} / \mathrm{ml}, 730 \mathrm{pCi} / \mathrm{ml}$ ). During the experimental period specimens were fed dead Tisbe bolothuriae once a week, the copepods were always eaten by the gammarids immediately.

Measurements were carried out of $\mathrm{pH}$, temperature (ranging from $16.8^{\circ} \mathrm{C}$ to $25.7^{\circ} \mathrm{C}$ for all experiments undertaken), culture water activity and specimen activity. The handling procedure was as follows: the specimens were separately placed on a $100 \mu \mathrm{m}$ mesh sieve and washed twice with $10 \mathrm{ml}$ uncontaminated brackish water. From the last $2 \mathrm{ml}$ of the second wash water $1 \mathrm{ml}$ was taken for radioactivity measurement to ensure that the specimen was free from the culture water activity. The results for these measurements always lay within the background experimental error. The last millilitre of water was used to keep the specimen wet during counting. After measurement the specimen was then returned to the experimental container.

The same procedure was used to measure the uptake of americium by Gammarus duebeni from aged contaminated water. The specimens chosen for this experiment had moulted one day prior to the start of the experiment and thus the positions within their moulting cycles were known. After the end of the uptake period these specimens were used to study the biological half-life of americium. The gammarids were introduced into new uncontaminated plastic containers (same design as used in uptake) which were placed in $200 \mathrm{ml}$ fresh uncontaminated water. Measurements were then carried out on $\mathrm{pH}$, temperature, culture water and specimen activity. Water changes were carried out regularly every 3-4 days for a period of up to 19 days, after which time the experiment was discontinued.

Some preliminary studies were made of the possible uptake of americium from contaminated food. Due to difficulties in distinguishing between the uptake by the gammarids from activity desorbed from the food into the water and the direct uptake from food itself, a more detailed experimental programme is being planned and it is hoped to report the findings at a later date. 


\section{Nereis diversicolor}

The uptake from water by Nereis diversicolor O. F. Müller was studied in two series of experiments with specimens caught in the wadden sea near the island of Sylt. The first series consisted of using freshly prepared americium solution and the second series with water that had been allowed to age between 5 to 6 days after the introduction of the americium. The method in both cases was as follows: a solution of $400 \mathrm{ml}$ contaminated sea-water $(30 \%, \mathrm{pH} 8.3)$ was prepared, the water having previously been filtered through a Seitz-filter ( $\mathrm{K}$ 5). The solution was transferred to a plastic basin containing 4 plastic perforated tubes (diameter $5 \mathrm{~cm}$, height $5 \mathrm{~cm}$ ). Each tube contained approximately 5 Raschig Rings which had been found to be indispensable for the health of the worms as they enabled them to get rid of excreta and secreted mucus by rubbing against the glass surfaces and edges.

After transfer of the radioactive solution one millilitre was immediately taken as zero-time standard (approximately $1200 \mathrm{cpm} / \mathrm{ml}, 680 \mathrm{pCi} / \mathrm{ml}$ ). Four worms which had previously been kept in sediment in the laboratory for a period of several weeks to months were weighed and then introduced into the four tubes which were submerged in the fresh or aged water. During the experiment the worms were each given a little fish food (commercially available TetraMin) once a week. Measurements of $\mathrm{pH}$, water activity and temperature (ranging from $20.7-23.1^{\circ} \mathrm{C}$ ) were made regularly every one to two days.

During uptake the worms were prepared for counting in the following way: each specimen was separately transferred to a $100 \mu \mathrm{m}$ mesh filter and washed twice with $10 \mathrm{ml}$ uncontaminated sea-water $(33-34 \%$ ). Great care was taken to separate the worms from any slime threads adhering to them. It was found that these threads concentrated activity to a very high level. In the great majority of cases no slime threads were observed due to the very efficient effect of the Raschig Rings, in the odd case where slight slime threads were visible, they were carefully removed. The fact that the threads were easy to detect and remove permitted a great degree of assurance in the measurements of the activity uptake. Of the last $2 \mathrm{ml}$ of the second $10 \mathrm{ml}$ wash water, $1 \mathrm{ml}$ was taken to keep the worms wet during counting. Wash water activity was always found to be within the experimental background error. One millilitre of culture water was also taken for counting and then returned to the experimental solution after measurement. A plastic top closing the experimental container ensured that negligible evaporation occured during the experimental period.

The uptake pathway of americium from contaminated sediments was also investigated. In this experiment 18 worms were introduced in the experimental system as described by Murray \& Renfro (1976), and allowed to accumulate activity for periods of 5,13 and 20 days, respectively. At the end of each time period 6 worms were removed from the sediment, carefully washed and then placed in uncontaminated sediment for 24 hours. It was considered that any ingested contaminated sediment would be excreted during this time. The worms were then placed in uncontaminated seawater for a further 12 hours in order to be absolutely sure that they were free of ingested particulate material. Chemical analysis of the worms was carried out according to the method of Murray \& Statham (1976). At each time interval a sediment sample was 
taken to determine if any systematic variations of the adsorbed activity had occurred. Only variations within the experimental error of the method were noted, indicating that the americium was extremely strongly bound to the sediment under the experimental conditions employed.

\section{RESULTS}

\section{Tisbe bolotburiae}

Although the results for the three experiments on the uptake of americium from water have quite a high variability they are all of a similar form. In Figure 1 it can be seen that uptake is extremely rapid and on average $74 \%$ of the steady state value (2-7 days) is reached in the first 24 hours. The americium in the water during the first two days decreases on average by about $60 \%$ (Fig. 2). In the control experiment, with no specimens present but containing $50 \mathrm{mg}$ uncontaminated food, the rapid formation

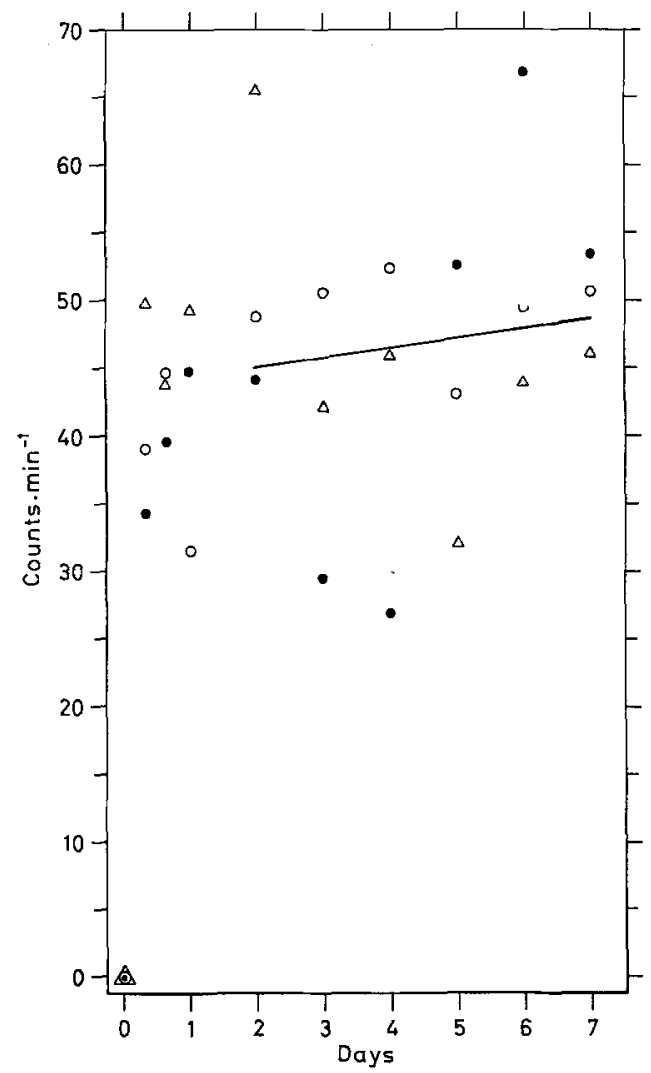

Fig. 1: Tisbe holothuriae. Uptake of ${ }^{243} \mathrm{Am}$ from contaminated water. Each sign represents activity of 50 female specimens. Results of three experiments 


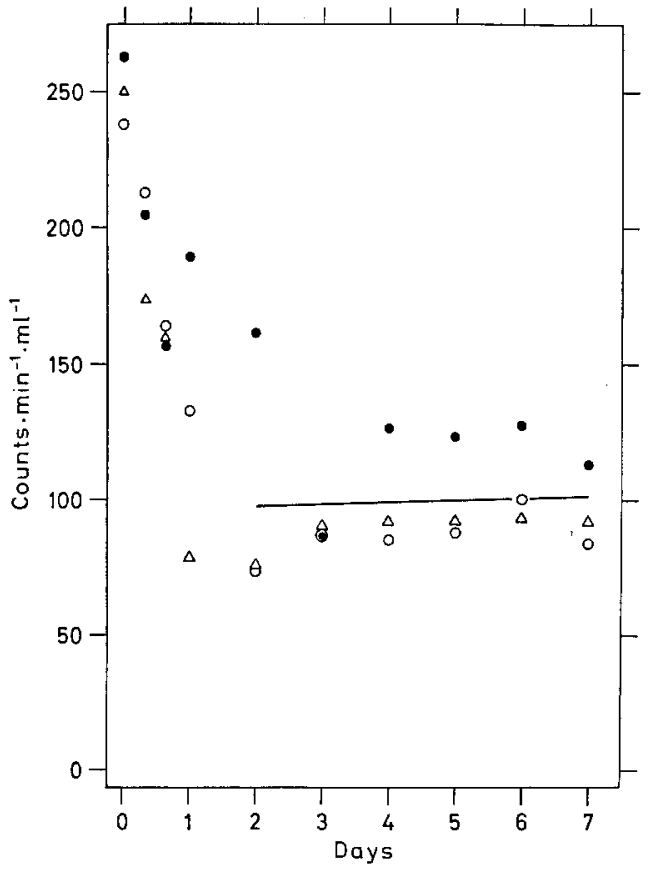

Fig. 2: Tisbe bolothuriae. Loss of ${ }^{243} \mathrm{Am}$ from water during uptake experiments

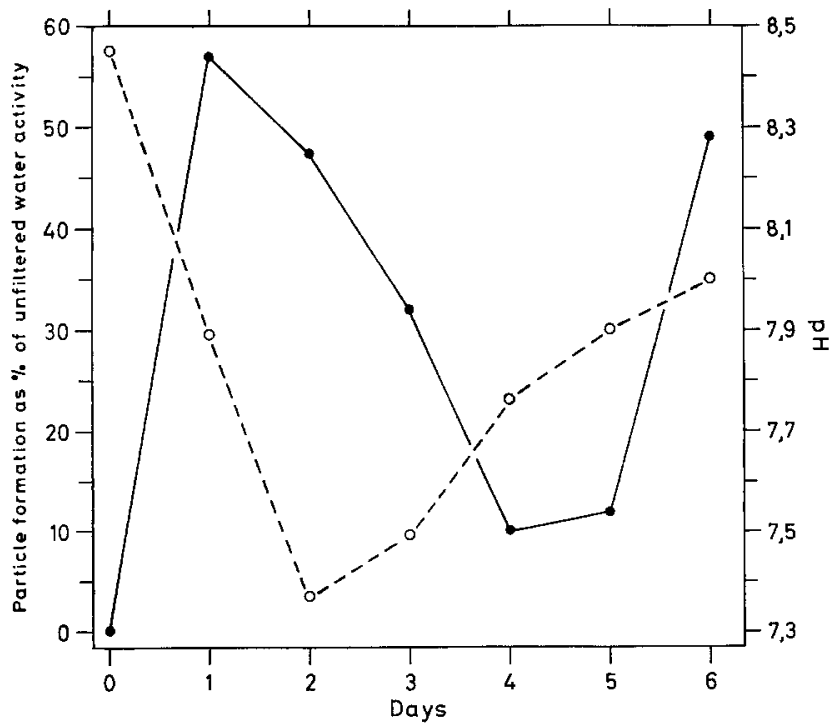

Fig. 3: Control experiment. Variation of ${ }^{243} \mathrm{Am}$ particle formation $(\bullet)$ and $\mathrm{pH}(0) .50 \mathrm{mg}$ uncontaminated food added 


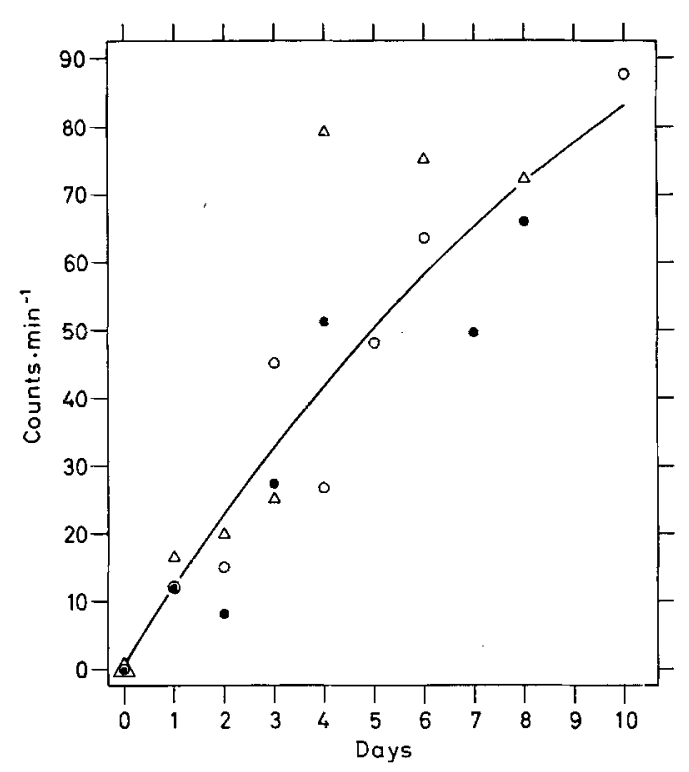

Fig. 4: Tisbe holotburiae. Uptake of ${ }^{243} \mathrm{Am}$ from contaminated food. Each sign represents activity of 50 female specimens. Results of three experiments

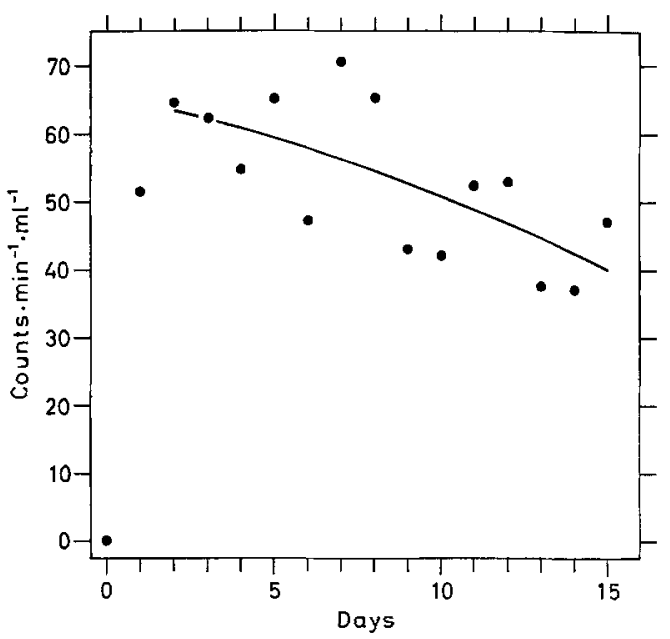

Fig. 5: Control experiment. Desorption of ${ }^{243} \mathrm{Am}$ from contaminated food into initially uncontaminated water

of particles seems linked to an equally rapid decrease in $\mathrm{pH}$ (Fig. 3). The particle formation reached a maximum of $57 \%$ of the total activity present in the water on day 1 and then decreased to $10 \%$ by day 4 ; the $\mathrm{pH}$ reached a minimum value on day 2 and then slowly increased until day 6 . Tisbe bolotburiae appeared to reach equilibrium activity after 2 days (cf. Fig. 1). The results for the three experiments were 
pooled for the period 2-7 days and regression analysis of the data showed that no significant changes occurred over this time. The mean concentration factor for this period has been calculated to be 1070 on a wet weight basis. The weight of the adult female specimen has been measured according to the procedure reported by Hoppenheit (1975b). Based on the specimens' activity after 2 days, it was determined that about $6 \%$ of the initial activity had been taken up by copepods compared to a $60 \%$ loss of activity from the water; the specimens were thus not responsible for the main loss from water and this is considered to be due to adsorption to the walls of the experimental containers.

Unlike the uptake of americium from water alone, the uptake of activity from contaminated food steadily increased in Tisbe bolotburiae during the period of the experiment; that is up to ten days (Fig. 4). An analysis of variance yielded no significant departure from linearity $(\alpha \gg 0.10)$. Although the activity levels measured also include the activity of the food ingested, it is obvious that this source alone cannot explain the steadily increasing body burden in the copepods from a consideration of the activity of the food compared to that of the specimens. Fifty milligrams wet weight food contained about $3600 \mathrm{cpm}{ }^{243} \mathrm{Am}$; in order to obtain a body activity of about $65 \mathrm{cpm}$ after 7 days, the weight of ingested food would have to be about $1 \mathrm{mg}$ per 50 specimens. This value is about 2 times greater than the average weight of 50 individuals which was determined to be $0.46 \mathrm{mg}$. An experiment with $50 \mathrm{mg}$ dry weight contaminated food but without specimens is shown in Figure 5; the water activity increased very rapidly in the first two days and then decreased slowly. A test of the results between days $2-15$ for departure from linearity yielded no significant deviation $(\alpha \gg 0.10)$ and the regression coefficient was found to be significantly different from zero at the 0.01 probability level. Thus the differences in the shape of the two uptake curves, either from contaminated water or food, is a further indication that although the desorbed food activity in the water could have contributed a small fraction of the measured body activity, the major fraction was due to the absorption of activity from the ingestion of contaminated food.

\section{Gammarus duebeni}

The results of the experiment on uptake of activity in Gammarus duebeni males from freshly prepared contaminated water are shown in Figure 6. The results are considered according to the specimen's phase within its moulting cycle at the start of the experiment.

The two Gammarus duebeni individuals shown in Figure 6a which had moulted 1 day before the experiment began, exhibited strong uptake during the first 6-7 days and reached an activity plateau after 10 days; at this time a concentration factor of about 300 (wet weight basis) was found. After day 10, one individual started to lose activity at approximately constant rate until death on day 29 , the other died on day 15.

The uptake by specimens that moulted 9 to 10 days after the start of the experiment is shown in Figure 6b. For the period before moulting, uptake appeared con- 
siderably less than for the individuals shown in Figure 6a. A slight decrease in body activity can be seen after moulting (indicated by arrows), due to the loss of the adsorbed moult activity. A rapid increase of body activity occurred directly afterwards and a plateau was reached after day 11; concentration factors at this time were 176 and 157 , respectively. They are about half those calculated for individuals which

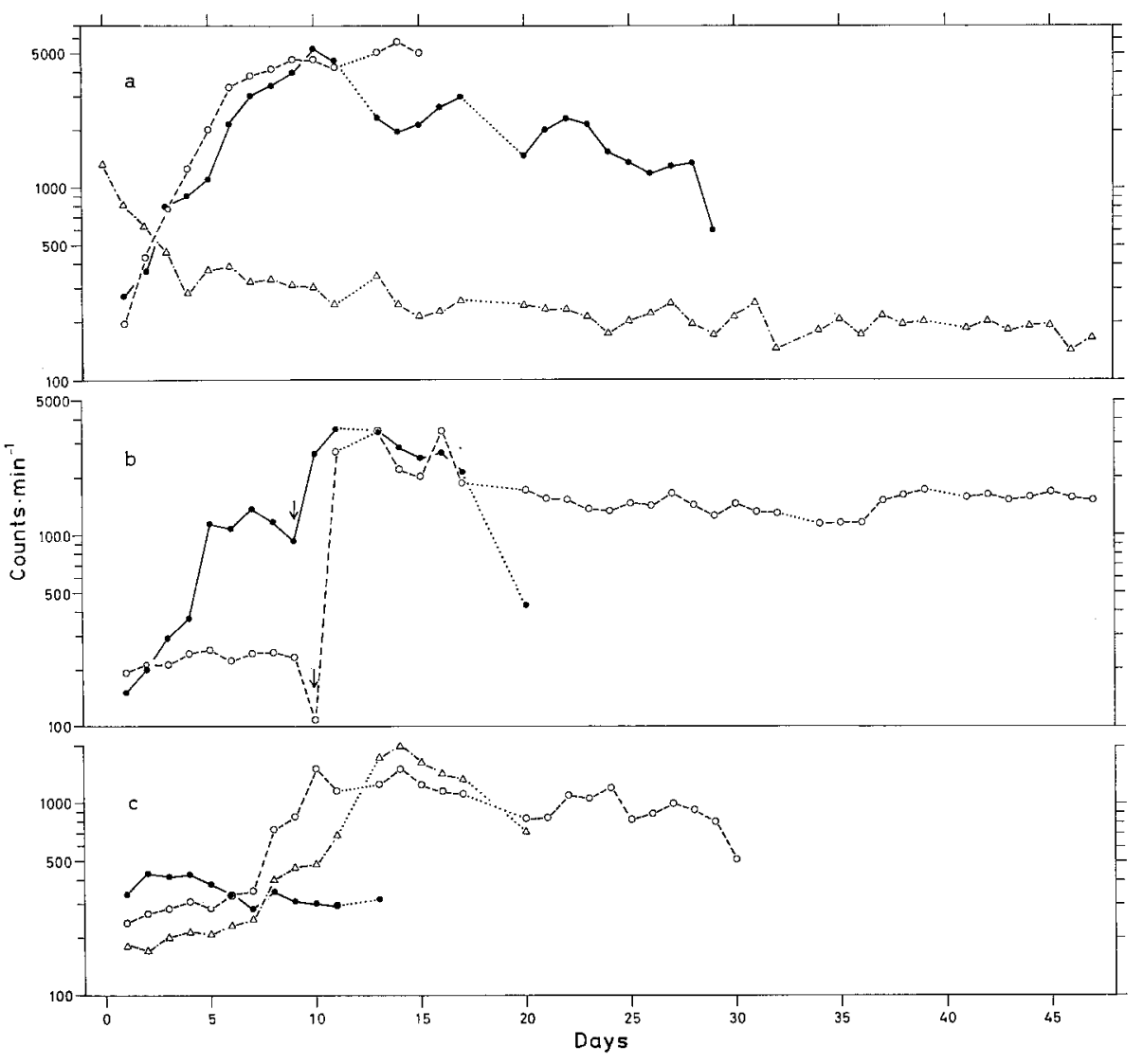

Fig. 6: Gammarus duebeni. Uptake of ${ }^{243} \mathrm{Am}$ from freshly prepared contaminated water. (For explanation see text)

moulted just before the start of the experiment (cf. Fig. 6a). As with the specimen that died on day 29 (cf. Fig. 6a) a large decrease in americium body burden is exhibited by the gammarid which died on day 20 . One individual which survived until the end of the experiment on day 47 , exhibited a steady body activity although this was less than the level reached by the gammarid in Figure 6a directly after moulting.

For specimens shown in Figure $6 \mathrm{c}$ no details concerning their positions within the intermoult periods are known. As death and date of moulting are known to be related (Hoppenheit, 1969), it is assumed that the experiment started at different moments within the intermoult periods. Two of the three individuals show similar tendency on 
uptake, increasing to a maximum on day 14 and then decreasing thereafter until death. The tendency to lose activity was shown, to a lesser or greater degree by all gammarids before their death.

A series of experiments has been undertaken on the uptake and loss from aged water in specimens that moulted one day before the start of the experiment. An example is given in Figure 7. Brackish water, being initially adjusted to $\mathrm{pH}$ 8.0, was contaminated with americium and allowed to age for 8 days before the introduction of the male adults. A fast initial uptake occurred within the first two days, a stable plateau being established slightly under the level reached on day 10. A concentration factor over this period of about 40 has been calculated. In the parallel experiments similar results were obtained, concentration factors ranging from 7 to 18.

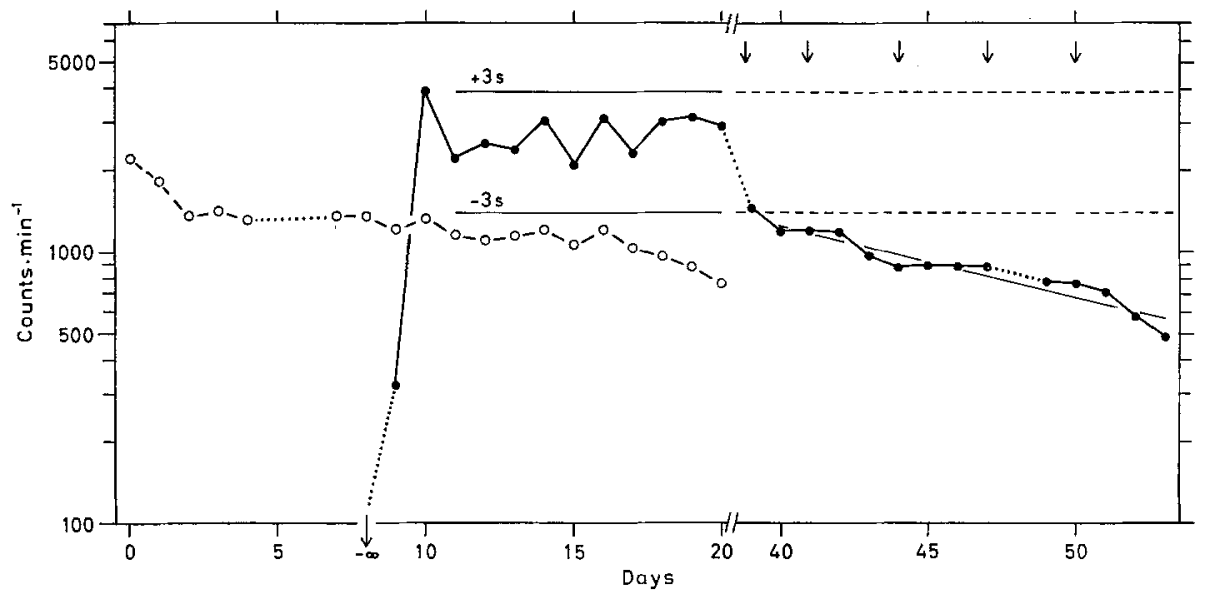

Fig. 7: Gammarus duebeni. Uptake and loss of ${ }^{243} \mathrm{Am}$ from aged water in a specimen that moulted one day before the start of the experiment. Loss of ${ }^{243} \mathrm{Am}$ from water given by open circles. Renewals of water indicated by arrows

The Gammarus duebeni male of Figure 7 was transferred on day 38 to an uncontaminated beaker containing $200 \mathrm{ml}$ uncontaminated water. A loss of body activity could be immediately measured and this continued throughout the second half of the experiment. From a regression analysis of the loss data, a biological half-life of 12.0 days was calculated. Two parallel experiments resulted in biological half-lives of 11.3 and 10.8 days, respectively.

Work carried out on the biology and physiology of Gammarus duebeni (Kinne, 1953) has shown that the moulting cycle for adult Gammarus duebeni males used in these experiments varies between 29 and 37 days at $18^{\circ} \mathrm{C}-20^{\circ} \mathrm{C}$. Although life expectancy of newly caught individuals varies, a fraction of them always survives to exhibit moulting several times. In the present studies in which contamination was both from water and food (food data not reported here), it was noted that of 25 specimens, for which moulting was known to have occurred on the day before start of experiment, 8 survived between $38-71$ days. Of these 8 , four died without moulting (regular inspections precluded the possibility of a moult occurring and the remains not being 
noticed), two moulted on days 47 and 61, respectively, and then immediately died. The remaining two lived until the end of experiments on days 47 and 71 , respectively, without moulting. The remaining 17 gammarids lived between 2 and 37 days before dying, that is within the intermoult period, and did not moult. Althogh a higher mortality is to be expected at elevated temperatures the non-appearance of moults in 6 of the 8 specimens surviving for more than 37 days may be an indication of a radiation effect. Such a suspicion is supported by the findings of Hoppenheit (1969) who reported that moulting can be delayed by a single exposure to $\mathrm{X}$-rays. The findings of Kinne (1953) that specimens maintained at high temperatures during their entire life show strongly prolonged moulting intervals must be taken into consideration; however, in the present work Gammarus duebeni were collected as adults in the field and used after only a few weeks (two or more) of adaptation to laboratory conditions, i. e. equivalent to a short part of their total life span.

The general conditions under which the experiments were conducted were as follows: mean temperature $21^{\circ} \mathrm{C} \pm 1.6^{\circ} \mathrm{C}$ (one sigma limits), americium water activities $10-700 \mathrm{nCi} / 1$, food activities $5-75 \mathrm{nCi} / \mathrm{g}$. Further experiments are at present being undertaken to support or to disprove the hypothesis presented.

\section{Nereis diversicolor}

Two experiments consisting of 4 worms each were performed on the americium uptake by Nereis diversicolor from aged water; no significant differences in the results were observable. Figure 8 shows the uptake as counts per minute for one of the experiments.

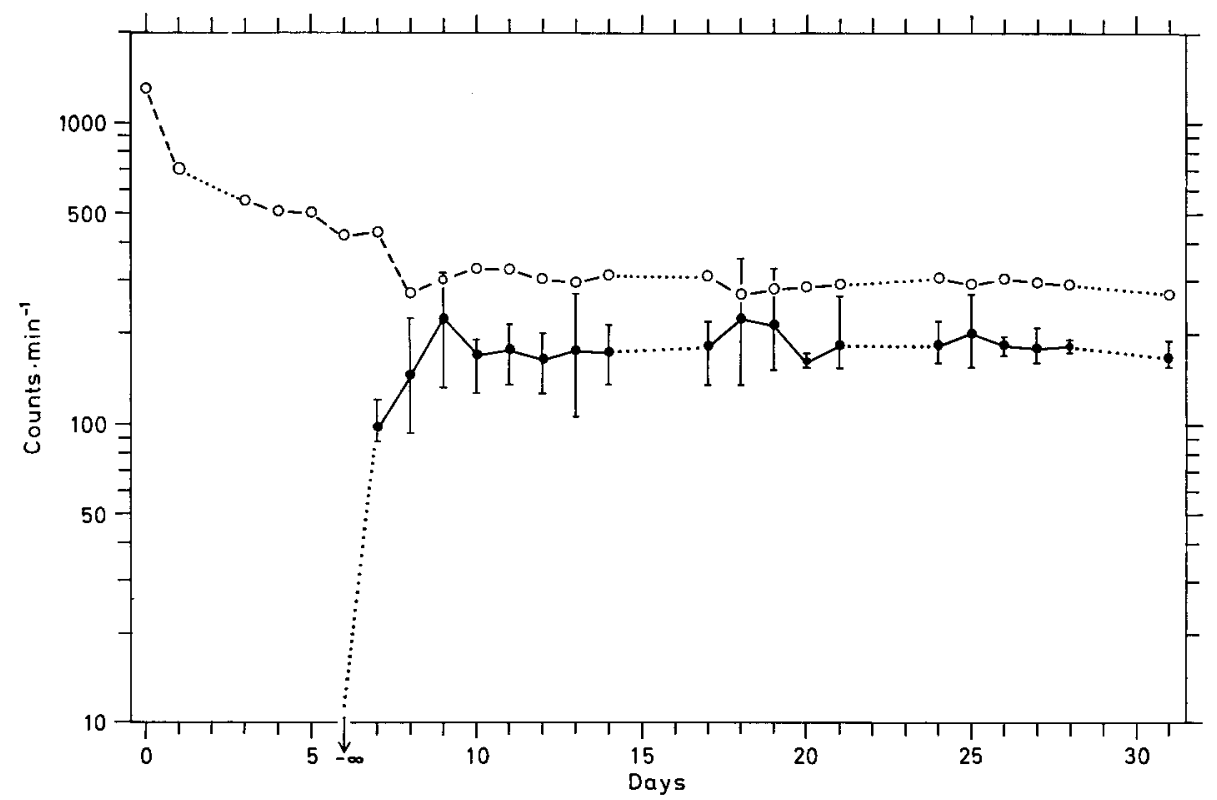

Fig. 8: Nereis diversicolor. Uptake of ${ }^{243} \mathrm{Am}$ from aged water. Points and bars represent mean and range of 4 specimens. Loss of ${ }^{243} \mathrm{Am}$ from water given by open circles 


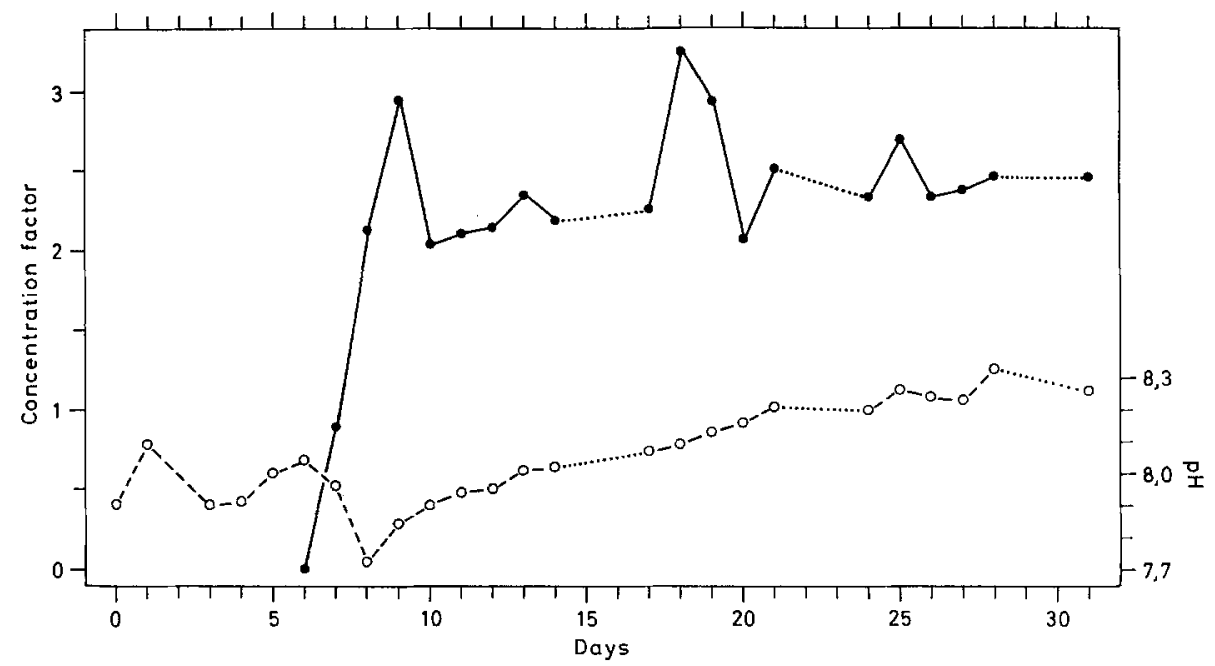

Fig. 9: Nereis diversicolor. Uptake of ${ }^{243} \mathrm{Am}$ from aged water. Variation of concentration factor $(\bullet)$ and $\mathrm{pH}(0)$. Points represent mean of 4 specimens

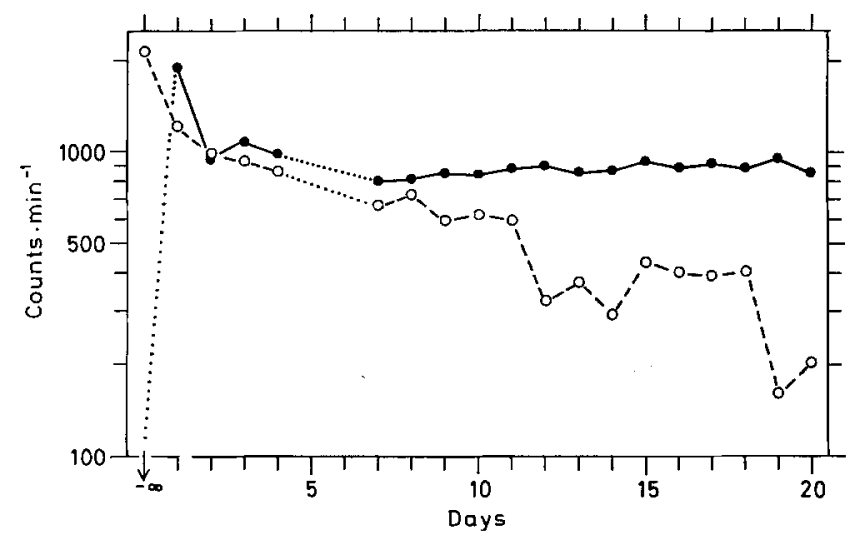

Fig. 10: Nereis diversicolor. Uptake of ${ }^{243} \mathrm{Am}$ from freshly prepared contaminated water. Loss of ${ }^{243} \mathrm{Am}$ from water given by open circles

The variation of concentration factor with variation in $\mathrm{pH}$ is plotted in Figure 9. As can be seen the uptake of americium by the worms from the aged water is extremely rapid and it would seem that near equilibrium is reached under these experimental conditions within a few days. It appears that the americium in freshly prepared solutions (Fig. 10) is more available to the worms than from aged contaminated seawater. For day 20 a concentration factor of 16 has been calculated in the case of the individual of Figure 10. In a parallel experiment the specimen reached a concentration factor of 21 over the same period of time.

From Figure 8 can be seen that the initial rapid uptake was followed by a long period during which the americium water and worm activity varied only to a small 


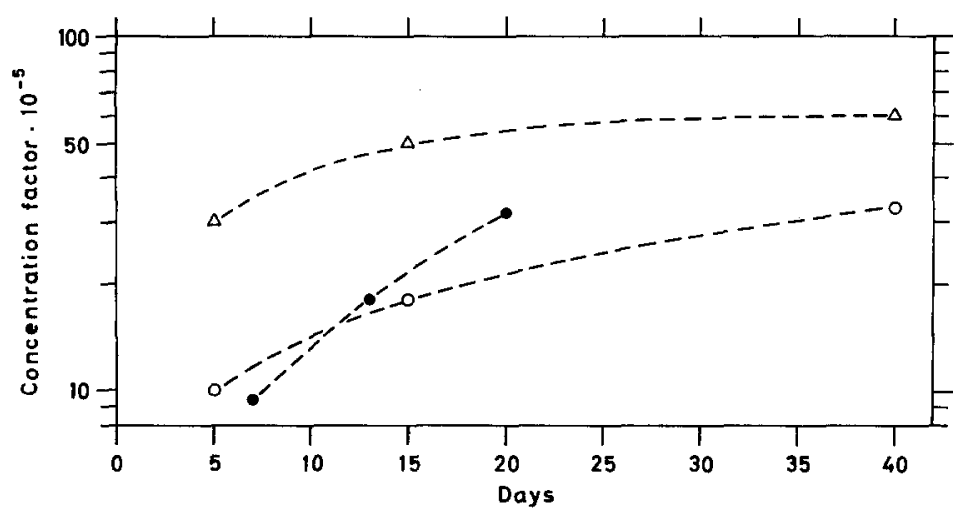

Fig. 11: Nereis diversicolor. Uptake of ${ }^{243} \mathrm{Am}$ from laboratory-contaminated Mediterranean sediment $(\bullet)$. Data of uptake from Windscale $(\Delta)$ and Bikini $\left({ }^{\circ}\right)$ sediments after Beasley \& Fowler (1976). Concentration factors calculated from worm and sediment activities per $\mathrm{g}$ wet. Curves fitted by eye

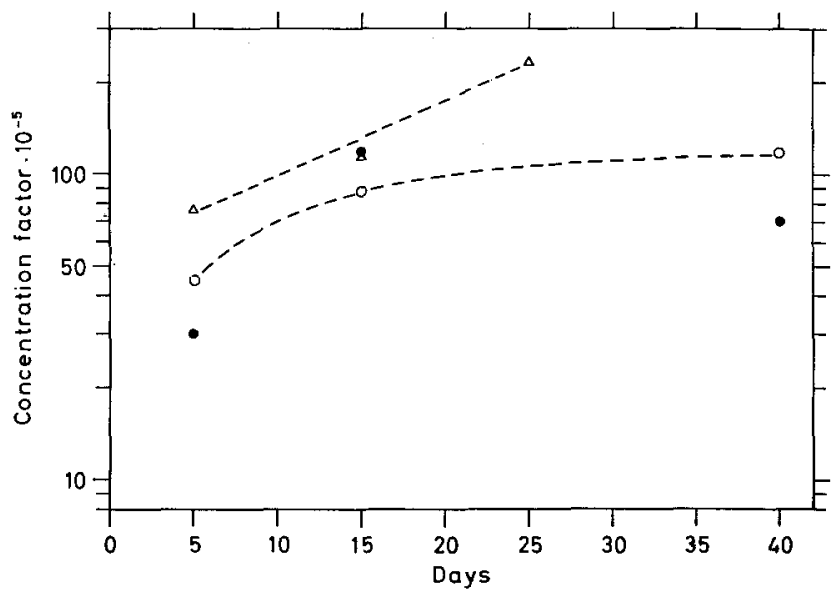

Fig. 12: Nereis diversicolor. Uptake of ${ }^{299} \mathrm{Pu}$ from laboratory-contaminated Mediterranean sediment after Murray \& Renfro (1976) $(\triangle)$ and Beasley \& Fowler (1976) in Bikini $(\bullet)$ and Windscale $(0)$ sediments. Concentration factors calculated from worm and sediment activities per $\mathrm{g}$ wet. Curves fitted by eye

degree. Concentration factors for the eight worms after 20 days of uptake ranged from about 2 to 4 . Figure 9 shows that $\mathrm{pH}$ decreases rapidly after introduction of the worms with a corresponding rapid uptake of activity. The lowest $\mathrm{pH}$ values were reached after 2 and 6 days, respectively. After this low point the $\mathrm{pH}$ and the uptake increased slowly over the remaining experimental period.

The uptake of americium by Nereis diversicolor from laboratory-contaminated Mediterranean sediments is plotted in Figure 11. Also shown are results for uptake of ${ }^{239} \mathrm{Pu}$ obtained by Murray \& Renfro (1976) (Figure 12), and americium and plutonium from Bikini- and Windscale-contaminated sediments (Beasley \& Fowler, 1976). 
It can be seen from the data that the rates of uptake of americium and plutonium after the fifth day are similar and the differences in the activity levels occur therefore within the first few days of the experiments; the enhanced uptake of plutonium over that of americium noted by Beasley \& Fowler (1976) is also shown by the present data.

\section{DISCUSSION}

\section{Tisbe bolotburiae}

Of the three invertebrate species studied in the present work, the concentration factors from water show a strong tendency to increase (Nereis diversicolor $<$ Gammarus duebeni $<$ Tisbe holothuriae) with decreasing size of the species; it would thus appear that surface adsorption may substantially contribute to the uptake of americium by these species. In the case of the copepods it can be further shown that uptake via contaminated food can supply an important fraction to its total body burden.

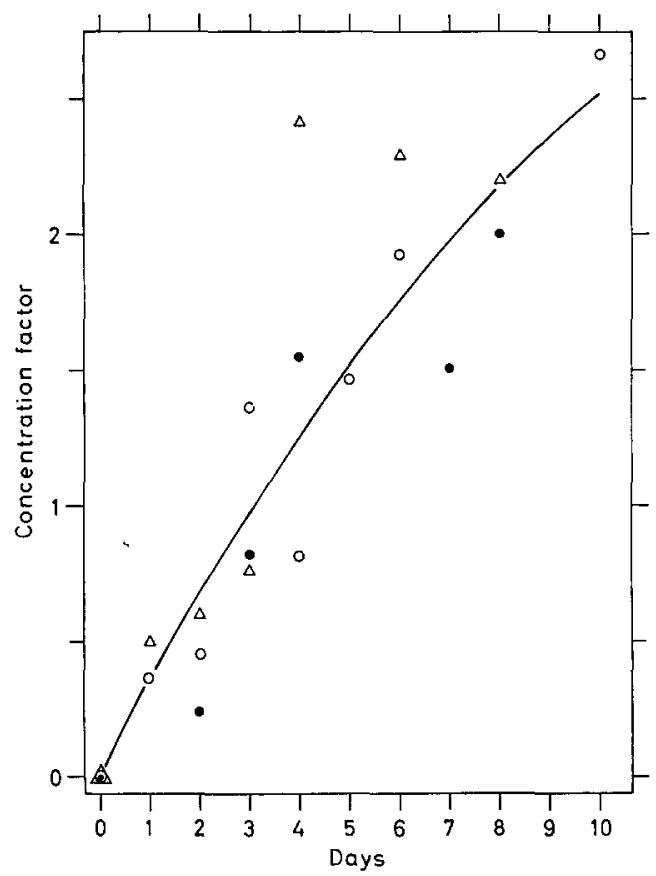

Fig. 13: Tisbe holothuriae. Uptake of ${ }^{243} \mathrm{Am}$ from contaminated food. Variation of concentration factor. Each sign represents 50 females. Concentration factors calculated from copepods and food activities per $\mathrm{g}$ wet. Results of three experiments

Although it is possible that in the present uptake experiments from food a certain fraction of the copepods body burden is obtained from food-desorbed americium via water, it would in fact appear that different mechanisms are responsible for the two 
uptake pathways. The concentration factor calculated for food is about 2, on a wet weight basis after 7 days (cf. Fig. 13). Although this concentration factor is small the effect on the total body burden of americium in Tisbe bolothuriae can be important and obviously depends greatly on the degree of contamination of the food that is consumed. In the present experimental system the body burdens reached after 7 days by the two pathways turned out to be similar and thus the two uptake routes contribute equally to the contamination of Tisbe bolothuriae. Under conditions where the food eaten by Tisbe bolothuriae is itself contaminated from water with a concentration factor similar to that of the copepod-water concentration factor, then the food and water pathways contribute equally to the copepods' total body burden. In the case where the food has a higher concentration factor, this pathway becomes correspondingly more important. The fact that such relatively high activities could be taken up by copepods has obviously important implications in the transfer of americium between different trophic levels of the marine food chain.

\section{Gammarus duebeni}

The differences exhibited in uptake by Gammarus duebeni from fresh and aged contaminated water are possibly associated with the formation and equilibrium conditions of the physico-chemical forms of americium in the water. The concentration factor of 300 found in newly moulted Gammarus duebeni males (cf. Fig. 6a) that had been introduced into freshly prepared contaminated water is nearly an order of magnitude higher than that found for specimens introduced into aged contaminated water

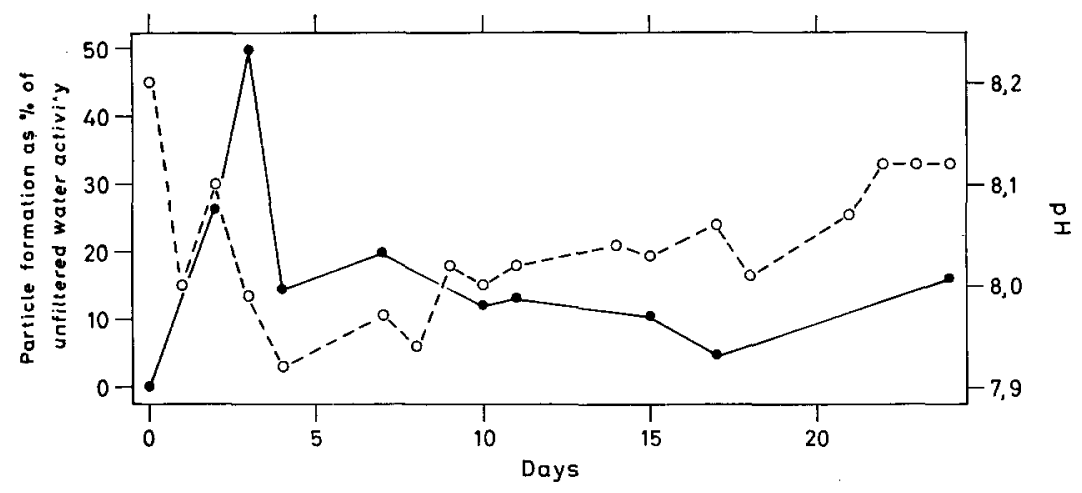

Fig. 14: Control experiment. Variation of ${ }^{243} \mathrm{Am}$ particle formation $(\bullet)$ and $\mathrm{pH}(0)$ in brackish water without specimens of Gammarus duebeni

(cf. Fig. 7). An explanation for these differences may perhaps be found by comparison to the control experiment (Fig. 14), in which the variation of the distribution of americium between particulate material in the water and fraction passing through the filter (expressed as a percentage of unfiltered water activity) is shown. It can be seen that the system fluctuates greatly in the first days after the addition of activity. The 
suspended particulate fraction rises to $50 \%$ of the total activity in the water on day 3 ; the $\mathrm{pH}$ drops initially from 8.2 to 8.0 on day 1 and recovers to 8.1 by day 2 only to drop back to $\mathrm{pH} 7.93$ by the fourth day, by which time the particulate fraction had decreased to $15 \%$ of the activity in the water. For the remainder of the experiment the particle fraction varied between $5-20 \%$ of the water activity; the $\mathrm{pH}$ increased slowly from its low point on day 4 to $\mathrm{pH} 8.12$ by day 24 , the last day of the experiment. It seems, therefore, that the large variations in $\mathrm{pH}$ and particle fraction that occur in the brackish water in the first few days may have an imporant influence on the uptake of the isotope by the specimens from unaged water. Thus, it is possible that the introduction of the test specimens into freshly contaminated water could lead to changes in the physico-chemical behaviour of americium which may alter its subsequent availability to the organisms. That differences in the physico-chemical equilibrium reactions occur primarly in the first few days after the addition of the isotope alone, or the isotope and the specimens, is further born out by the fact that the animals did not appear to have a conditioning effect on aged contaminated water. This was demonstrated by comparing the concentration factor for specimens introduced into initially aged water that had already been used for uptake experiments, with concentration factors for unconditioned aged water. No differences in the results obtained were found.

A phenomenon noticeable in the present uptake experiments, carried out with freshly prepared contaminated water (cf. Fig. 6), was that after day 14 there was a steady decrease in the uptake levels of americium which was accompanied by a general decrease in both the temperature and $\mathrm{pH}$ over the same period. Results on uptake from aged water have shown that increasing body activities can occur together with steadily increasing $\mathrm{pH}$, this effect being observed over a period of up to 36 days at a fairly constant temperature of $21.8^{\circ} \mathrm{C} \pm 0.8^{\circ} \mathrm{C}$; it would thus appear that an uptake mechanism for americium which is related to $\mathrm{pH}$ may be implicated. Merlini \& Pozzi (1977) have demonstrated that the accumulation of lead by the sunfish Leporis gibbosus is significantly increased when the $\mathrm{pH}$ is lowered and these workers proposed that this was probably due to the fact that under more acid conditions there is an increase in the ionic fraction of lead $\left(\mathrm{Pb}{ }^{++}\right)$, thus enhancing the ability of fish to concentrate it. Murray \& Fukai (1975) have shown that the formation of americium particles in freshwater and sea-water is strongly dependent upon variations in $\mathrm{pH}$, especially in the range $\mathrm{pH} 7.5-8.5$; it would thus seem likely that if an adsorption mechanism depending upon particle formation plays an important role in the uptake of americium by Gammarus duebeni, a decrease in particle formation at lower $\mathrm{pH}$ could lead to a decrease in its uptake. If on the other hand uptake is related to non-particle absorption then it might be expected that in solutions of lower $\mathrm{pH}$, enhanced uptake would occur due to an increase in possible ionic species (complexes) of the actinides leading to greater bioavailability. Experiments are at present underway to verify or disprove these hypotheses. 


\section{Nereis diversicolor}

As appears to be the case with Gammarus duebeni, it seems possible that physicochemical reactions of americium occurring in freshly contaminated culture water may also play an important role in its bioavailability for polychaete worms. Experiments on the percentage of activity bound on particulate matter in sea-water, with and without the introduction of worms, were carried out over a 7-8 day period; these are shown in Figure 15. The worms were introduced into the water in order to observe their effect on the formation of particles during the period of greatest variation. As had been noticed with gammarids, the biggest change in $\mathrm{pH}$ and particulate fraction occurred within this time. From the figure it will be seen that the sea-water, with and without worms, had initially the same $\mathrm{pH} 8.2-8.25$. In the case of sea-water containing worms the $\mathrm{pH}$ immediately decreased to 7.95 in the following 24 hours and thereafter continued to descend until day 4 then it reached $\mathrm{pH} 7.82$. The sea-water without worms showed an initial increase of $\mathrm{pH}$ over the first 24 hours to $\mathrm{pH} 8.26$ and thereafter showed a slight decrease to $\mathrm{pH} 8.14$ on day 3 , its maximum range after the seven days

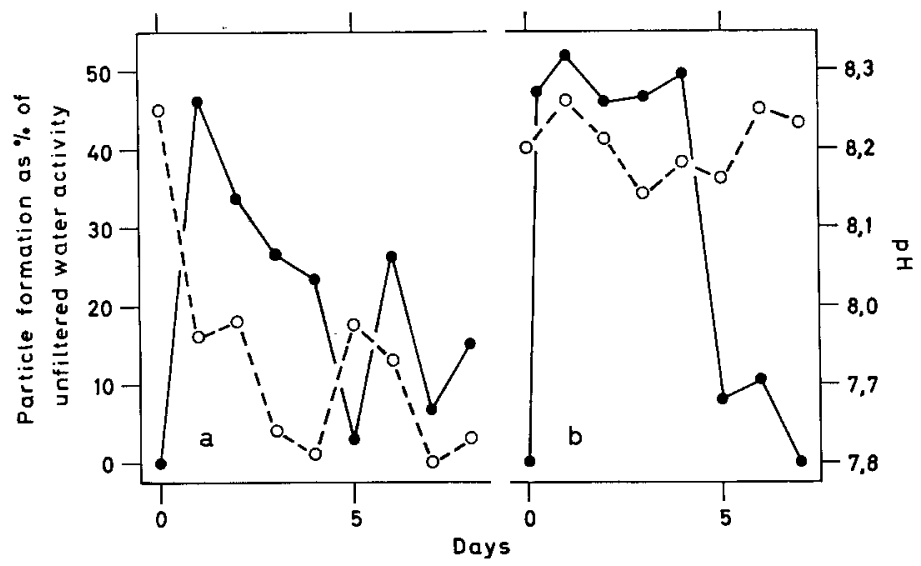

Fig. 15: Control experiments. Variation of ${ }^{243} \mathrm{Am}$ particle formation $(\bullet)$ and $\mathrm{pH}(0)$ with (a) and without (b) specimens of Nereis diversicolor

being only $0.12 \mathrm{pH}$ units. The percentage of activity remaining on a $0.45 \mu \mathrm{m}$ filter for samples of both waters showed a large increase in the first 24 hours of between $45-50 \%$, but thereafter the sea-water containing the worms steadily decreased until day 5 , when it readed a minimum value of $3 \%$. The sea-water containing no worms continued to have a high percentage of particles until day 4; during the following 24 hours its particle fraction then decreased to $9 \%$. It is thus evident that in the initial period of 3 to 4 days large differences occur in the $\mathrm{pH}$ and particle fraction between the two solutions. The authors believe that mechanisms connected with these variations account for the differences observed in the uptake of americium from fresh or aged water.

Again, as with Gammarus duebeni, the americium availability in aged water, for 
polychaetes, appears to be unaffected by the secretion of mucopolysaccharides, mucoproteins etc. and other conditioning processes. This was shown by introducing specimens into contaminated water, previously conditioned by other specimens over periods of days up to several weeks; the uptake of these specimens showed the same form and reached similar levels of activity as did specimens added to water aged only 5-8 days but having not previously contained worms. The fact that the aging of actinides in water in the initial few days can play such an important role in their subsequent bioavailability may well explain the results of Fowler et al. (1975) who found that the uptake of plutonium was markedly reduced for worms introduced into water previously used for uptake experiments. In the present work concentration factors for americium after 20 days of uptake from aged water for two experimental series ranged from 2-4 (wet weight basis). The increased uptake of americium in freshly prepared seawater is shown in Figure 10, a concentration factor after 20 days of 16 is reached, some 5 times greater than from an equivalent aged solution.

In the case of sediments, it is doubtful if this aging effect would be observable as the preparation of contaminated samples requires considerable time in which physico-chemical processes would be able to occur and stabilize the chemical form of americium. In the present work (cf. Fig 11) the uptake of americium $(+3$ form) from laboratory-contaminated sediments was studied. The system used was the same as that described by Murray \& Renfro (1976) who had earlier investigated the relative contribution to plutonium $(+4)$ uptake by Nereis diversicolor from sea-water and sediment pathways. Comparing the results of absorption of americium and plutonium isotopes from sediments it is evident that there is an enhancement of plutonium over americium in the worms of about seven times; this enhancement is very similar to that found for those elements in uptake experiments undertaken by Beasley \& Fowler (1976) using naturally contaminated sediments from the region of Windscale in the Irish Sea. In a similar series of experiments using contaminated sediments from the nuclear weapon testing area in Bikini Islands, Beasley $\&$ Fowler (1976) found a much greater variability in this enhancement which was 12 times greater on the fifth day, 25 times greater on the fifteenth day and 8 times greater on the fortieth day. In the present work the rate of uptake of americium and plutonium from Mediterranean sediment by the polychaetes appears generally similar to that found by Beasley \& Fowler (1976) for their two sediments during the period day 5 until days 20-25. The differences in measured body burdens (cf. Figs. 11 and 12) must thus occur within the first 5 days of uptake. The fact that the concentration factors for americium in the present work are similar to those found for the Bikini sediments may well be related to a similarity of the chemical forms of americium. The difference exhibited by Windscale-contaminated sediment from the other two contaminated sediments may, on the other hand, reflect changes in chemical speciation occurring during fuel re-processing and subsequent discharge of wastes.

It is particularly interesting to note that when a comparison is made of the uptake of plutonium by polychaetes from water found by Fowler et al. (1975) and the uptake of americium from water in the present work, the enhancement of plutonium over americium after 15 days is about 50; this is some 7 times greater than the enhancement factor for its uptake from sediments which has been found to be about 7. A possible 
explanation for this difference in enhancement factors for water and sediment may well be related to the concentration factor found by Fowler et al. (1975). This concentration factor was calculated for plutonium $(+4$ and +6 forms) based on the uptake by polychaete worms apparently introduced into freshly prepared contaminated seawater; after 7 days a factor of about 160 was found, and after 15 days a factor of 200 for plutonium $(+6)$. On introducing fresh worms into the same water but after a period of conditioning a concentration factor for plutonium $(+6)$ after 7 days of about 43 was found (after this time the experiment was apparently discontinued). Taking this concentration factor for water and comparing it to that for americium of about 4 found in the present work, the ratio for the enhancement reduces to about 10 , a value in very reasonable agreement with the average enhancement for plutonium over americium in sediment which is 7 . The differences in uptake from the freshly prepared and aged solutions of americium are again considered to be due to physicochemical processes taking place within the first few days after introduction of the radioisotope.

Employing the method discussed by Murray \& Renfro (1976), for comparing the relative contribution of sea-water and sediment pathways to americium uptake by Nereis diversicolor, it would appear that water is the more important, although not to such a great extent as has been found for plutonium.

\section{CONCLUSIONS}

(a) The initial conditions under which the physico-chemical reactions of americium (and possible plutonium) occur in the first few days after its introduction into brackish water or sea-water appear to play an important role on the isotope's subsequent bioavailability.

(b) The mechanism regulating americium uptake in different species may be closely linked to $\mathrm{pH}$. It might be expected that if uptake processes involve more soluble species of americium then they will be enhanced by lower $\mathrm{pH}$ conditions; processes related to surface particle adsorption would probably become more effective at higher $\mathrm{pH}$.

(c) In the three invertebrate species studied, the concentration factors for americium increase markedly with decreasing physical size. Under the simulated environmental conditions employed in the present work $(\approx \mathrm{pH} 8)$ this may reflect the fact that the regulating mechanism of uptake is one of adsorption.

(d) The polychaete worm Nereis diversicolor shows an enhanced uptake of plutonium over americium from both water and sediment. The relative contribution from these two pathways to its total americium body burden appears similar to that found for plutonium, the major fraction being due to uptake from water.

(e) The copepod Tisbe bolotburiae is able to obtain an important fraction of its total americium body activity from food. If its food source were to be very highly contaminated this pathway could become the controlling factor in its uptake of this actinide.

Acknowledgements. The authors thank Mrs. I. Ziehr for her assistance in the experiments and Miss R. Kleinfeld for drawing the figures. 


\section{LITERATURE CITED}

Beasley, T. M. \& Fowler, S. W., 1976. Plutonium uptake from contaminated sediments by the polychaete Nereis diversicolor. Mar. Biol. 38, 95-100.

Bishop, W. P. (Ed.), 1975. Seabed disposal program. A first-year report December 1974. Sandia Lab. Rep. Sand 74-0410, 1-511.

Fowler, S. W., Heyraud, M. \& Beasley, T. M., 1975. Experimental studies on plutonium kinetics in marine biota. In: Impacts of nuclear releases into the aquatic environment. IAEA, Vienna, 157-177.

Girardi, F. \& Bertozzi, G., 1974. Long-term $\alpha$-hazard of high activity waste from nuclear fuel reprocessing. Commission of the European Communities, EUR 5214 e, 1-30.

Hessler, R. R., 1974. The structure of deep benthic communities from central oceanic waters. In: The biology of the oceanic Pacific. Oregon State Univ. Press, Corvallis, 79-93.

Hoppenheit, M., 1969. Strahlenbiologische Untersuchungen an Gammariden (Crustacea, Amphipoda). Helgoländer wiss. Meeresunters. 19, 163-204.

- 1975a. Zur Dynamik exploitierter Populationen von Tisbe holothuriae (Copepoda, Harpacticoida). I. Methoden, Verlauf der Populationsentwicklung und Einfluß der Wassererneuerung. Helgoländer wiss. Meeresunters. 27, 235-253.

- 1975b. Zur Dynamik exploitierter Populationen von Tisbe holothuride (Copepoda, Harpacticoida). II. Populationsdichte, Alterszusammensetzung, Wachstum und Ausbeute. Helgoländer wiss. Meeresunters. 27, 377-395.

- 1976. Zur Dynamik exploitierter Populationen von Tisbe bolothuriae (Copepoda, Harpacticoida). III. Reproduktion, Geschlechtsverhältnis und Überlebenszeit. Helgoländer wiss. Meeresunters. 28, 109-137.

Kinne, O., 1953. Zur Biologie und Physiologie von Gammarus duebeni Lillj., II.: Über die Häutungsfrequenz, ihre Abhängigkeit von Temperatur und Salzgehalt, sowie über ihr Verhalten bei isoliert gehaltenen und amputierten Versuchstieren. Zool. Jb. (Allg. Zool. Physiol. Tiere) 64, 183-205.

McGowan, J. A., 1976. Water column biology: A preliminary account. Biological structures in the North Pacific Central Gyre. In: Seabed disposal program. Annual report JanuaryDecember 1975. Ed. by D. M. Talbert. Sandia Lab. Rep. Sand 76-0256, 88-96.

Merlini, M. \& Pozzi, G., 1977. Lead and fresh water fishes: Part I. Lead accumulation and water pH. Environ. Pollut. 12, 167-172.

Murray, C. N. \& Fukai, R., 1975. Adsorption-desorption characteristics of plutonium and americium with sediment particles in the estuarine environment. In: Impacts of nuclear releases into the aquatic environment. IAEA, Vienna, 179-192.

- \& Renfro, W., 1976. Uptake of plutonium from seawater and sediments by a marine polychaete worm. J. oceanogr. Soc. Japan 32, 167-172.

- \& Statham, G., 1976. Application of a solvent extraction procedure using di-2-ethyl hexyl phosphoric acid (HDEHP) for the separation of some transuranic elements in environmental samples. Dt. hydrogr. Z. 29, 69-75.

Pigford, T. H. \& Ang, K. P., 1975. The plutonium fuel cycles. Health Phys. 9, 451-468.

Talbert, D. M. (Ed.), 1976. Seabed disposal program. Annual report January-December 1975. Sandia Lab. Rep. Sand 76-0256, 1-729.

Uhlig, G., 1965. Die mehrgliedrige Kultur litoraler Folliculiniden. Helgoländer wiss. Meeresunters. 12, 52-60.

Ward, E. E., 1966. Uptake of plutonium by the lobster Homarus vulgaris. Nature, Lond. 209, 625-626. 